\title{
Editorial
}

\section{Language: Processes and Problems}

The development of speech and language has always been an interesting topic in its own right. The area has become of increasing interest to educational and developmental psychologists as knowledge of the roles of speech and language in the acquisition of literacy and the development of social skills grows.

One aspect of language that has come increasingly under the spotlight is that of phonological awareness, so perhaps it is not surprising that in this special edition on language processes and problems the majority of the articles deal with some facet of this topic. The role of phonological awareness in the acquisition of literacy skills is being increasingly discussed in school circles as packaged programs, designed to develop phonological awareness, are being promoted in schools. Their use with children of very young ages is advocated by many teachers and parents yet strongly criticised by others as being unnecessary or inappropriate for the preschool years. The review paper that opens this edition examines phonological development as it relates to reading development and provides an overview of research into phonological awareness training programs. The following three papers present research being carried out in Australia that looks at various aspects of the phonological awareness link with literacy. Together they provide a basis for readers to more confidently answer questions such as: Who is at risk for phonological and literacy difficulties? How can we identify children at risk? What aspects of phonological awareness are important? What type of children can benefit from phonological awareness training programs? At what age should any such programs be implemented and by whom?

Our fifth paper is far removed from the previous theme. It examines the role of mother-child conversations in the development of theory of mind for children with autism, Asperger syndrome and specific language impairment. It is a timely reminder of the risks researchers run of coming to premature conclusions, when these are based on data drawn from too few groups of participants and too limited contexts.

In the final paper of this special issue we turn to language development in the normally developing child with an investigation of the emergence of word comprehension. It is likely to be a provocative paper as it raises questions concerning the methodology most appropriate for assessing comprehension in preverbal children.

When I looked over the papers in this issue and noted their source, I was struck by the fact that two of the first authors completed their original training as speech pathologists and still practise as such. It reinforced for me the belief that, as psychologists, we can gain broader perspectives and new insights into problems, through collaborations with colleagues in allied professions who share our concerns.

Janet Fletcher Guest Editor 